\title{
Fenologia do alecrim-pimenta (Lippia sidoides Cham.) em área de Cerrado, no norte de Minas Gerais, Brasil
}

CARVALHO JÚNIOR, W.G.O.*; MELO, M.T.P.; MARTINS, E.R.

Instituto de Ciências Agrárias, Universidade Federal de Minas Gerais, ICA/UFMG, CEP: 39404-006, Montes ClarosBrasil *carvalhojunior17@yahoo.com.br

\begin{abstract}
RESUMO: Este trabalho teve como objetivo descrever o comportamento fenológico de Lippia sidoides Cham., em área de Cerrado, no norte de Minas Gerais, buscando-se subsidiar o processo de domesticação da espécie, por meio do estudo da ocorrência e duração das fenofases vegetativas e reprodutivas da espécie, bem como avaliar a influência dos fatores climáticos da região em cada fenofase, e ainda verificar a sincronia dessas fenofases entre os indivíduos. Vinte indivíduos foram avaliados mensalmente no período de fevereiro de 2007 a fevereiro de 2009, quanto à intensidade e sincronia das fenofases de brotamento, folhas maduras, senescência foliar, floração, frutificação e queda foliar. Houve acentuada periodicidade na ocorrência dos eventos fenológicos foliares, sendo que essa periodicidade acompanhou a estacionalidade climática da região, evidenciando a forte influência dos fatores abióticos, principalmente da precipitação e umidade relativa do ar. O alecrim-pimenta apresentou comportamento caducifólio, com alta taxa de queda foliar durante grande parte do ano. A floração ocorreu no período de fevereiro a abril, enquanto a frutificação alcançou o pico de intensidade no mês de maio. Todas as fenofases apresentaram altos índices de sincronia, sendo esse um fator facilitador do manejo da espécie.
\end{abstract}

Palavras-chave: plantas medicinais, manejo, fenofases, fatores climáticos

\begin{abstract}
Pepper-rosmarin (Lippia sidoides Cham.) phenology in a Cerrado area in northern Minas Gerais State, Brazil. The aim of this work was to describe the phenological behavior of Lippia sidoides Cham. in a Cerrado area in northern Minas Gerais State, Brazil, in order to contribute to the process of domestication of this species by studying the occurrence and duration of its vegetative and reproductive phenophases, evaluating the influence of local climatic factors on each phenophase and investigating the synchrony of these phenophases among individuals. Twenty specimens were monthly evaluated between February 2007 and February 2009 as to intensity and synchrony of the phenophases sprouting, mature leaves, leaf senescence, flowering, fruiting and leaf abscission. There was great periodicity in the occurrence of leaf phenological events according to the local climatic seasonality, highlighting the strong influence of abiotic factors, especially rainfall and relative air humidity. Pepper-rosmarin showed deciduous behavior, with high leaf abscission rate during a great part of the year. Flowering occurred from February to April, whereas fruiting peaked in May. All phenophases had high levels of synchrony, a facilitating factor for the management of this species.
\end{abstract}

Key words: medicinal plants, management, phenophases, climatic factors

\section{INTRODUÇÃO}

Dentre as plantas utilizadas com propósitos medicinais, o alecrim-pimenta (Lippia sidoides Cham.) destaca-se como espécie que teve o cultivo ampliado em vários estados brasileiros, devido à inclusão em programas de fitoterapia (Matos \& Oliveira, 1998), estando inclusive listada na Relação Nacional de Plantas Medicinais de Interesse ao Sistema Único de Saúde, a Renisus. Trata-se de arbusto densamente ramificado, nativo do semiárido nordestino, de até três metros de altura, com ramos providos de folhas muito aromáticas e picantes (Lorenzi \& Matos, 2002). O óleo essencial, extraído das folhas do alecrim-pimenta, é composto principalmente por mono e sesquiterpenos,

Recebido para publicação em 01/09/2009

Aceito para publicação em 31/05/2010

Rev. Bras. Pl. Med., Botucatu, v.13, n.2, p.223-229, 2011. 
destacando-se o timol como o constituinte majoritário (Terblanché \& Kornelius, 1996).

O potencial medicinal da espécie pode ser comprovado pela intensa atividade antimicrobiana apresentada pelo óleo essencial, como bem demonstram os trabalhos de Lemos et al. (1990), Fontenelle, (2005), Oliveira et al. (2006) e Botelho et al. (2007). Este óleo essencial possui ainda atividade moluscicida contra o caramujo Biomphalaria glabra, e larvicida contra o estágio aquático do mosquito da dengue, Aedes aegyptii (Lorenzi \& Matos, 2002; Cavalcanti et al., 2004).

O termo fenologia surgiu como contração de "fenomenologia", expressão primeiramente proposta por Charles Morren, em 1853 (Marchiori, 2004). Segundo Rathcke \& Lacey (1985), a palavra é derivada do grego phaino, que significa mostrar ou aparecer, definindo, portanto, a fenologia como o estudo do ritmo sazonal dos eventos cíclicos de vida de determinada espécie, sendo a ocorrência de cada evento fenológico crítica para os processos de sobrevivência e de reprodução dos organismos.

Para que o cultivo e o manejo das espécies vegetais sejam conduzidos de forma adequada, é essencial o entendimento da dinâmica dos ecossistemas onde essas espécies têm origem e desenvolvimento, sendo os estudos fenológicos uma ferramenta essencial para tal finalidade (d'Eça Neves \& Morellato, 2004). Além de permitir a compreensão da dinâmica das comunidades vegetais, o registro das características fenológicas é de grande importância por servir como indicador das respostas das plantas às condições climáticas e edáficas de determinada área (Fournier, 1974).

O estudo da fenologia de espécies vegetais com importância medicinal tem alcançado projeção no cenário científico, fato que se confirma pelo trabalho de Felfili et al. (1999), onde os eventos fenológicos de Stryphnodendron adstringens foram avaliados numa área de Cerrado sensu stricto. Também os estudos de Coelho \& Spiller (2008), com Heteropterys aphrodisiaca; Nunes et al. (2008), com Myracrodruon urundeuva; Caldeira Júnior et al. (2008), com Dimorphandra mollis e Santos et al. (2009), com Lafoensia pacari, integram o rol dos trabalhos que fornecem informações fenológicas de espécies utilizadas com propósitos medicinais.

Embora tenha sido comprovada a importância medicinal do alecrim-pimenta e seu processo de domesticação já ter sido iniciado (Oliveira et al., 2008; Figueiredo et al., 2009), dados sobre os eventos fenológicos dessa espécie são inexistentes. Essas informações fenológicas seriam relevantes por apresentarem as relações entre a espécie e o ambiente de ocorrência natural e, ainda, por fornecerem base para o adequado sistema de manejo no campo, contribuindo para a exploração mais eficiente e ecologicamente mais correta dos recursos oferecidos (Mariot et al., 2003).

Dessa forma, objetivou-se com este estudo descrever o comportamento fenológico de Lippia sidoides Cham., em área de Cerrado, no norte de Minas Gerais, buscando-se subsidiar o processo de domesticação da espécie, por meio do estudo da ocorrência e duração das fenofases vegetativas e reprodutivas da espécie, bem como avaliar a influência dos fatores climáticos da região em cada fenofase, e ainda verificar a sincronia dessas fenofases entre os indivíduos.

\section{MATERIAL E MÉTODO}

O estudo foi desenvolvido em uma área de 36,6 ha, da Fazenda Experimental Hamilton de Abreu Navarro do Instituto de Ciências Agrárias da Universidade Federal de Minas Gerais, em Montes Claros, norte de Minas Gerais (1641'00"S e 4350'00"W). Esta área avaliada se caracteriza fisionomicamente pelo predomínio do Cerrado sensu stricto. Na classificação de Koeppen (1948), o clima da região é o Aw, com uma estação seca bem definida e chuvas concentradas nos meses de novembro a janeiro.

Foi adotado o método de amostragem em trilhas, descrito por d'Eça Neves \& Morellato (2004), selecionando-se, ao acaso, 20 indivíduos de Lippia sidoides Cham., adultos e em condições fitossanitárias aparentemente satisfatórias (ausência de doenças e parasitas). Esses indivíduos foram marcados, com placa de alumínio numeradas, e georreferenciados, utilizando-se o sistema de posicionamento global.

As observações e coletas dos dados fenológicos foram realizadas mensalmente, de fevereiro de 2007 a fevereiro de 2009, totalizando 25 meses de observações. Foram registradas a presença ou ausência e intensidade das seguintes fenofases: (1) Brotamento: tendo início a partir do aparecimento de brotos foliares até a expansão total das folhas novas; (2) Folhas maduras: folhas completamente expandidas, com coloração verde escura; (3) Senescência foliar: notada pelo amarelecimento progressivo das folhas; (4) Floração: aparecimento dos botões florais até antese das últimas flores; (5) Frutificação: notada pelo fim da antese e posterior confirmação da existência de sementes; (6) Queda foliar: sempre que se notavam espaços vazios nos ramos ou quando eram observadas folhas caídas no solo logo abaixo do indivíduo.

Adotou-se a metodologia proposta por Fournier (1974) para quantificar as fenofases, a qual as avalia individualmente, utilizando uma escala intervalar semi-quantitativa de cinco categorias $(0 \mathrm{a}$ 4) e intervalo de $25 \%$ entre cada categoria, sendo $0=$ ausência da fenofase; 1 = presença da fenofase com magnitude entre 1 e $25 \% ; 2$ = presença da fenofase

Rev. Bras. PI. Med., Botucatu, v.13, n.2, p.223-229, 2011. 
entre 26 e $50 \% ; 3=$ presença da fenofase entre 51 e $75 \%$ e 4 = presença da fenofase entre 76 e $100 \%$.

Considerando a intensidade de cada fenofase, foi calculada a porcentagem de Fournier, segundo Fournier (1974). Na verificação da sincronia das diferentes fenofases na população, foi utilizado o Índice de Sincronia (Z), proposto por Pedroni et al. (2002). Os dados meteorológicos foram fornecidos pelo Instituto Nacional de Meteorologia do Ministério da Agricultura, Pecuária e Abastecimento (INMET/ MAPA) e obtidos na Estação Climatológica Principal de Montes Claros/MG, localizada a 200 metros da área do estudo.

A normalidade da distribuição dos dados foi testada por meio do Teste LF - LILLIEFORS, utilizando-se o software SAEG (Ribeiro Júnior, 2001). Uma vez que os dados não apresentaram distribuição normal, foi utilizada a análise de correlação de Spearman $\left(r_{s}\right)$ para verificar a relação entre as variáveis climáticas (precipitação total mensal, temperaturas máxima, média e mínima, umidade relativa média mensal e insolação total mensal) e a intensidade das fenofases.

\section{RESULTADO E DISCUSSÃO}

O brotamento ocorreu com maior intensidade nos meses em que a precipitação alcançava os maiores valores, atingindo o pico de intensidade em dezembro de 2008 (Figura 1). Essa mesma fenofase correlacionou-se significativa e positivamente com a precipitação $\left(r_{s}=0,83 ; P=0,0001\right)$, com a temperatura mínima $\left(r_{s}=0,71 ; P=0,0002\right)$, com a temperatura média $\left(r_{s}=0,52 ; P=0,0052\right)$ e com a umidade relativa $\left(r_{s}=0,57 ; P=0,0024\right)$. No entanto, apresentou correlação negativa e significativa com a insolação $\left(r_{s}=-0,75 ; P=0,0001\right)$, indicando que em períodos com grande insolação, a produção de brotos foliares é fortemente comprometida. Esse acontecimento pode ser explicado pelo fato de haver maior insolação em períodos de menor ou nenhuma incidência de precipitação, devido à ausência de nuvens. Coelho \& Spiller (2008), trabalhando com a espécie medicinal Heteropterys aphrodisiaca, observaram o mesmo padrão para a produção de brotos e folhas novas, relacionando esse fato à ocorrência do período chuvoso. Em conformidade com Borchert et al. (2002), as espécies caducifólias apresentam brotamento imediatamente após as primeiras chuvas, assim como pôde ser observado neste estudo, indicando que pequena quantidade de água disponível já seria suficiente para quebrar a dormência de gemas e induzir o brotamento.

Em relação às folhas maduras, a intensidade máxima foi atingida no mês de abril de 2008, exatamente um mês após a máxima precipitação registrada, contrastando com a queda foliar, que apresentou a menor intensidade neste mesmo mês. É interessante notar que quando correlacionadas essas fenofases com as variáveis climatológicas houve comportamento completamente antagônico, de forma que a queda foliar apresentou correlação

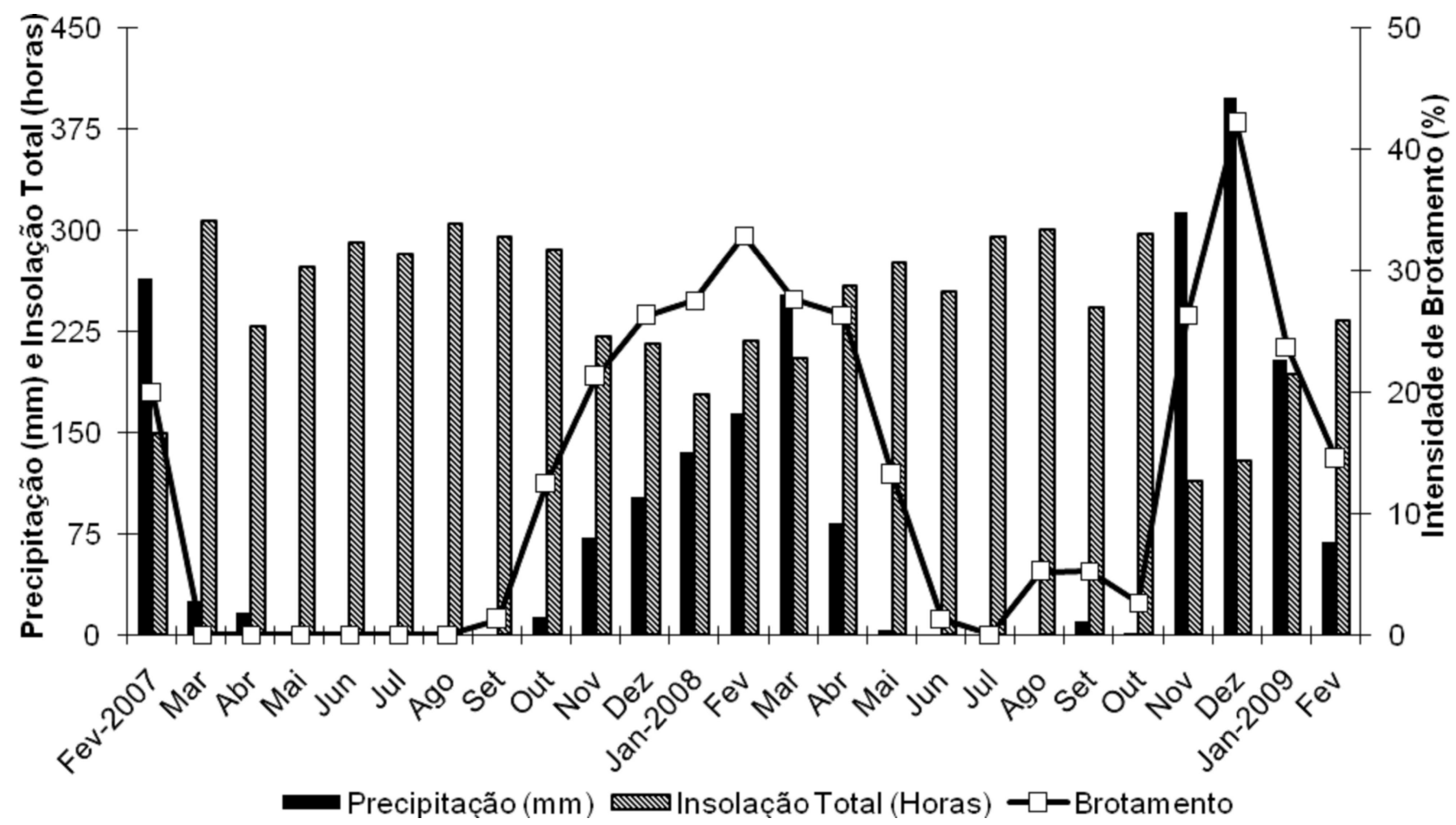

FIGURA 1. Intensidade de brotamento de alecrim-pimenta (Lippia sidoides Cham.) no período de fevereiro de 2007 a fevereiro de 2009 em correlação com a precipitação e com a insolação total. Montes Claros/MG. 
negativa e significativa com a precipitação $\left(r_{s}=-0,73\right.$; $\mathrm{P}=0,0002)$ e com a umidade relativa $\left(r_{s}=-0,91 ; P=\right.$ $0,0001)$, e correlação positiva com a insolação $\left(r_{s}=\right.$ $0,55 ; P=0,0035)$, enquanto a fenofase relativa às folhas maduras mostrou correlação positiva com a precipitação $\left(r_{s}=0,68 ; P=0,0004\right)$ e com a umidade relativa $\left(r_{s}=0,90 ; P=0,0001\right)$, e correlação negativa com a insolação $\left(r_{s}=-0,56 ; P=0,0030\right)$. Santos et al. (2009) sugerem a diminuição da pluviosidade como fator desencadeador da queda foliar em ambiente de cerrado.

Houve grande periodicidade na ocorrência dos eventos fenológicos foliares (Figuras 2 e 3), de forma que essa periodicidade acompanhou a estacionalidade climática da região, o que evidencia a forte influência dos fatores abióticos, principalmente da precipitação e da umidade relativa do ar, na ocorrência dos eventos de expansão (folhas maduras) e de abscisão foliar.

Apesar de também ter sido alta a correlação com a precipitação, a maior correlação entre a fenofase folhas maduras e as variáveis climatológicas foi obtida em relação à umidade relativa do ar. Esse resultado corrobora a proposição de Corlett (1987), que defende que o status hídrico da planta não depende somente da disponibilidade de água no solo, dada pela simples ocorrência de precipitação, mas da demanda evaporativa da atmosfera e, principalmente, da capacidade de transpiração do vegetal, que estaria mais ligada às variações da umidade relativa do ar.

Foi observado que o alecrim-pimenta apresenta comportamento caducifólio bem marcado no ambiente de ocorrência natural, sendo que em grande parte dos meses, de junho a novembro, apresenta-se com alta taxa de ausência de folhas. Esse fator é determinante para a exploração da espécie, visto que as folhas correspondem à principal parte da planta utilizada na medicina popular. Dessa forma, a prática da irrigação na produção comercial da espécie seria uma possível alternativa a ser adotada, visando à manutenção da produção de folhas.

Com relação à senescência foliar, não foram observados valores significativos de correlação com as variáveis climáticas e nem período de alta intensidade dessa fenofase, podendo-se somente observar que se trata de evento gradativo e que antecede a queda foliar.

A floração do alecrim-pimenta concentrouse no período de fevereiro a abril (Figura 4), podendo estender-se aos meses de maio e junho, porém com menor intensidade, e apresentou correlação positiva e significativa com a umidade relativa do $\operatorname{ar}\left(r_{s}=0,60 ; P\right.$

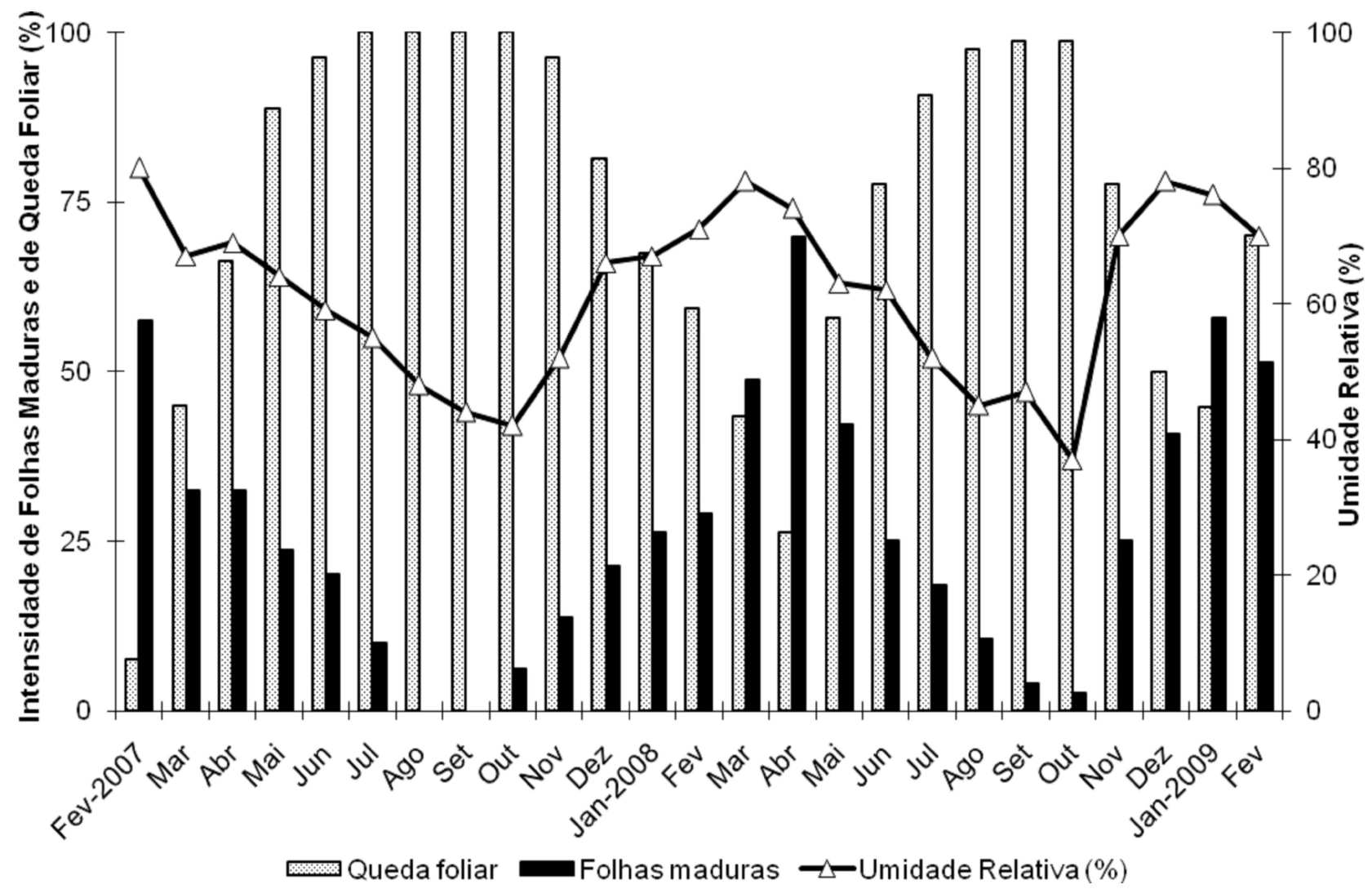

FIGURA 2. Intensidade de folhas maduras e de queda foliar de alecrim-pimenta (Lippia sidoides Cham.) no período de fevereiro de 2007 a fevereiro de 2009 em correlação com a umidade relativa do ar. Montes Claros/MG. 




FIGURA 3. Intensidade de folhas maduras e de queda foliar de alecrim-pimenta (Lippia sidoides Cham.) no período de fevereiro de 2007 a fevereiro de 2009 em correlação com a precipitação. Montes Claros/MG.

$=0,0018)$. Essa variável climatológica é um dos fatores ambientais apontado por Rathcke \& Lacey (1985) como determinante do início do processo de florescimento. Os outros fatores ambientais descritos por esses autores são o fotoperíodo e a temperatura. No entanto, o fotoperíodo seria fator relevante para ervas de vida curta (plantas anuais) e a temperatura afetaria o florescimento principalmente de espécies lenhosas adaptadas ao clima temperado ou de ervas perenes (Rathcke \& Lacey,
1985). No presente estudo não houve correlação significativa entre as temperaturas máxima, média ou mínima e o florescimento do alecrim-pimenta.

Já em relação à frutificação da espécie, percebe-se que essa fenofase alcançou o pico de intensidade nos meses de maio de 2007 e de 2008, logo após o pico de floração (Figura 4). Observou-se que no mês seguinte ao pico de frutificação, ocorre a dispersão da totalidade dos frutos, evidenciando um

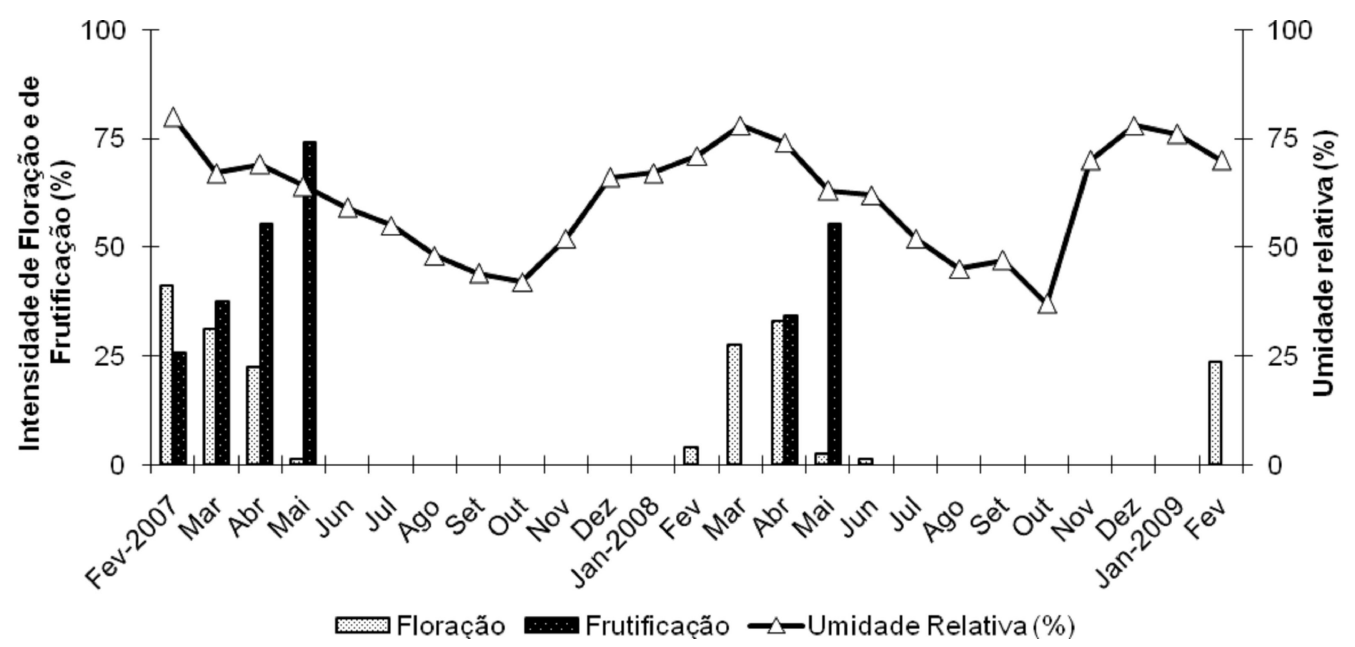

FIGURA 4. Intensidade de floração e de frutificação de alecrim-pimenta (Lippia sidoides Cham.) no período de fevereiro de 2007 a fevereiro de 2009 em correlação com a umidade relativa do ar. Montes Claros/MG. 
período muito curto para a produção de sementes, importante oportunidade para a propagação natural da espécie. Os valores de correlação entre a frutificação e as variáveis climáticas não foram significativos.

A Figura 5 ilustra, em detalhes, as fenofases do alecrim-pimenta.

Todas as fenofases apresentaram altos índices de sincronia, com destaque para a frutificação e queda de folhas (Tabela 1), sendo esse um fator que, de acordo com Caldeira Júnior et al. (2008), facilita o manejo da espécie no campo, já que a maioria das plantas apresentará a mesma fase fenológica, em determinado período.

As fenofases brotamento, folhas maduras, floração e queda foliar do alecrim-pimenta são fortemente influenciadas pelos fatores climáticos, especialmente por aqueles diretamente vinculados à disponibilidade de água para a planta, como a precipitação e a umidade relativa do ar. A população de alecrim-pimenta estudada apresentou-se altamente sincrônica, em especial quanto à frutificação e à queda de folhas. A marcada sazonalidade climática do norte de Minas Gerais está fortemente associada ao tipo de ciclo de vida do alecrim-pimenta, portanto, influenciando de maneira decisiva a exploração antrópica dos recursos oferecidos pela espécie. Os resultados, obtidos no presente trabalho, poderão servir de subsídio para

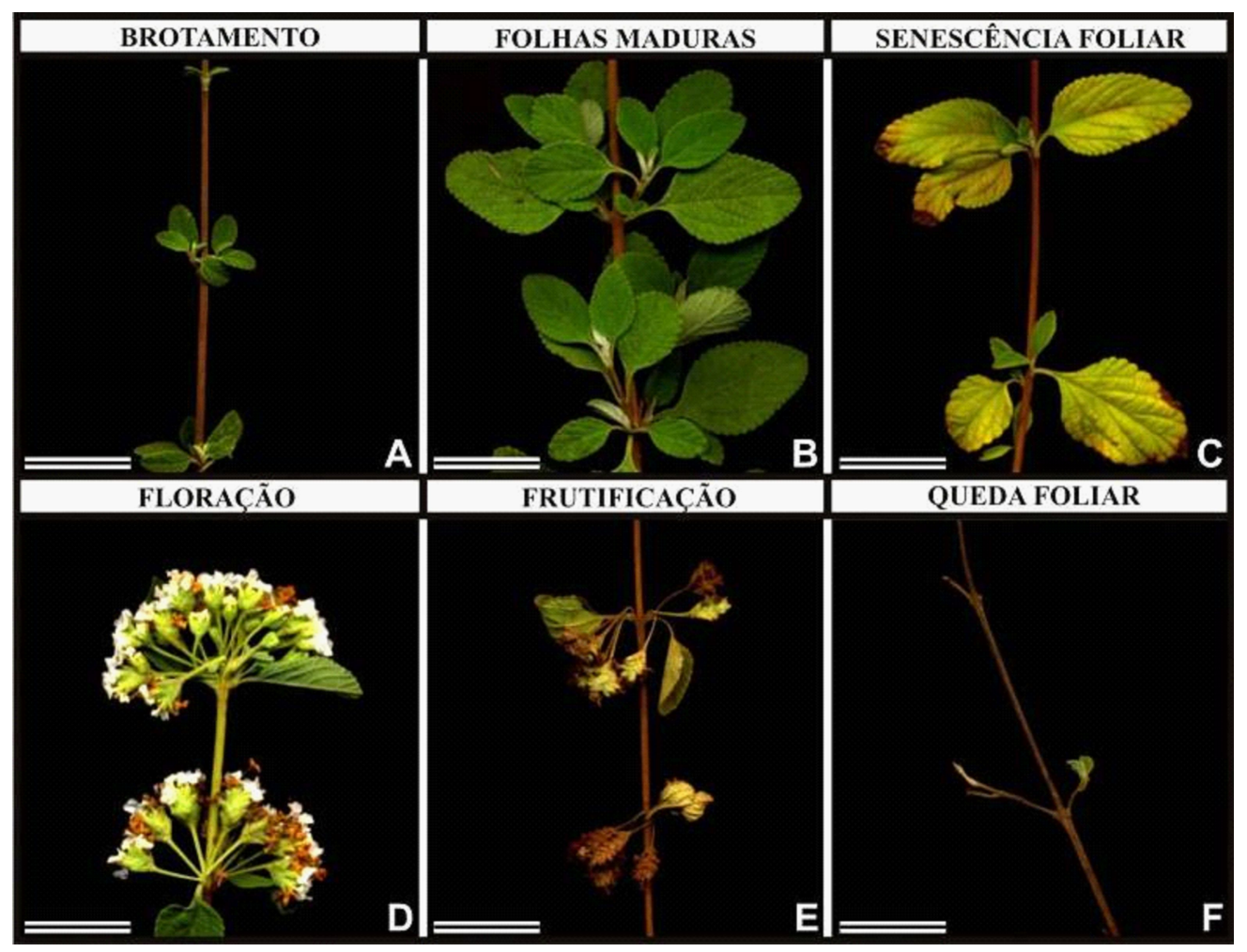

FIGURA 5. Fenofases do alecrim-pimenta (Lippia sidoides Cham.). Barra = 20 mm. Montes Claros/MG.

TABELA 1. Índice de Sincronia (Z) da população amostrada de alecrim-pimenta (Lippia sidoides Cham.) no município de Montes Claros, norte de Minas Gerais.

\begin{tabular}{lc}
\hline \multicolumn{1}{c}{ FENOFASES } & ÍNDICE (Z) \\
\hline Brotamento & 0,83 \\
Folhas maduras & 0,90 \\
Folhas em senescência & 0,86 \\
Queda foliar & 0,98 \\
Floração & 0,89 \\
Frutificação & 0,99 \\
\hline
\end{tabular}

nortear ações de cultivo e manejo do alecrim-pimenta, otimizando sua produção.

\section{AGRADECIMENTO}

Os autores agradecem ao Programa de Educação Tutorial (PET/Sesu/MEC) pela concessão de bolsa a Carvalho Júnior, W.G.O. e ao Conselho Nacional de Desenvolvimento Científico e Tecnológico (CNPq) pela concessão de bolsa a Melo, M.T.P. Ao professor Bruno Francisco Sant'Anna dos Santos, pelo valioso auxílio na documentação fotográfica deste manuscrito. Ao Fundo de Desenvolvimento Científico e Tecnológico do Banco do Nordeste do Brasil (BNB/ FUNDECI), pelo auxílio financeiro. 


\section{REFERÊNCIA}

BORCHERT, R.; RIVERA, G; HAGNAUER, W. Modification of vegetative phenology in a tropical semideciduous forest by abnormal drought and rain. Biotropica, v.34, p.381-93, 2002.

BOTELHO, M.A. et al. Antimicrobial activity of the essential oil from Lippia sidoides, carvacrol and thymol against oral pathogens. Brazilian Journal of Medical and Biological Research, v.40, p.349-56, 2007.

CALDEIRA JÚNIOR, C.F. et al. Fenologia da fava-d'anta (Dimorphandra mollis Benth.) no norte de Minas Gerais, Brasil. Revista Brasileira de Plantas Medicinais, v.10, n.4, p.18-28, 2008.

CAVALCANTI, E.S.B. et al. Larvicidal activity of essential oils from brazilian plants against Aedes aegyptii L. Memorial Instituto Oswaldo Cruz, v.99, n.5, p.541-4, 2004. COELHO, M.F.B.; SPILLER, C. Fenologia de Heteropterys aphrodisiaca O. Mach. - Malpighiaceae, em Mato Grosso. Revista Brasileira de Plantas Medicinais, v.10, n.1, p.17, 2008.

CORLETT, R. Leaf phenology in tropical trees. In: INTERNATIONAL CONFERENCE ON TROPICAL PLANT ECOPHYSIOLOGY, 31., 1985, Bogor, Indonesia. Proceedings... Bogor: Southeast Asian Regional Center for Tropical Biology, 1987. p.133-8.

d'EÇA NEVES, F.F.; MORELLATO, P.C. Métodos de amostragem e avaliação utilizados em estudos fenológicos de florestas tropicais. Acta Botanica Brasilica, v.18, n.1, p.99-108, 2004.

FELFILI, J.M. et al. Estudo fenológico de Stryphnodendron adstringens (Mart.) Coville no cerrado sensu stricto da Fazenda Água Limpa no Distrito Federal, Brasil. Revista Brasileira de Botânica, v.22, n.1, p.83-90, 1999.

FIGUEIREDO, L.S. et al. Influência do ácido indolbutírico no enraizamento de alecrim-pimenta (Lippia sidoides) em leito com umidade controlada. Revista Brasileira de Plantas Medicinais, v.11, n.1, p.33-6, 2009.

FONTENELLE, R.O.S. Avaliação do potencial antifúngico de óleos essenciais de plantas do nordeste brasileiro frente a diferentes cepas de Microsporium canis, Candida spp. e Malassezia pachydermatis. 2005. 81p. Dissertação (Mestrado - Área de Concentração em Reprodução e Sanidade Animal) Universidade Estadual do Ceará, Fortaleza.

FOURNIER, L.A. Un método cuantitativo para la medición de características fenológicas en árboles. Turrialba, v.24, n.4, p.422-3, 1974.

KOEPPEN, W. Climatologia: con un estudio de los climas de la tierra. Fondo de Cultura Econômica. 1948. 479p. LEMOS, T.L.G. et al. Antimicrobial activity of essential oil of Brazilian plants. Phytotherapy Research, v.4, n.2, p.824, 1990.

LORENZI H.; MATOS F.J.A. Plantas medicinais no Brasil: nativas e exóticas. Nova Odessa: Instituto Plantarum, 2002. 512p.

MARCHIORI, J.N.C. Elementos de dendrologia. 2.ed. Santa Maria: Editora UFSM, 2004. 176p.

MARIOT, A.; MANTOVANI, A.; REIS, M.S. Uso e conservação de Piper cernuum Vell. (Piperaceae) na Mata Atlântica: I. Fenologia reprodutiva e dispersão de sementes. Revista Brasileira de Plantas Medicinais, v.5, n.2, p.1-10, 2003.

MATOS, F.J.A.; OLIVEIRA, F. Lippia sidoides Cham. farmacognosia, química e farmacologia. Revista Brasileira de Farmacognosia, v.79, p.84-7, 1998.

NUNES, Y.R.F. et al. Aspectos ecológicos da aroeira (Myracrodruon urundeuva Alemão - Anacardiaceae): fenologia e germinação de sementes. Revista Árvore, v.32, n.2, p.233-43, 2008.

OLIVEIRA, F.P. et al. Effectiveness of Lippia sidoides Cham. (Verbenaceae) essential oil in inhibiting the growth of Staphylococcus aureus strains isolated from clinical material. Revista Brasileira de Farmacognosia, v.16, n.4, p.510-6, 2006.

OLIVEIRA, G.L. et al. Enraizamento de estacas de Lippia sidoides Cham. utilizando diferentes tipos de estacas, substratos e concentrações do ácido indolbutírico. Revista Brasileira de Plantas Medicinais,v.10, n.4, p.127, 2008.

PEDRONI, F.; SANCHEZ, M.; SANTOS, F.A.M. Fenologia da copaíba (Copaifera langsdorffii Desf. - Leguminosae, Caesalpinoideae) em uma floresta semidecídua no sudeste de Brasil. Revista Brasileira de Botânica, v.25, n.2, p.183-94, 2002.

RATHCKE, B.; LACEY, E.P. Phenological patterns of terrestrial plants. Annual Review of Ecology and Systematics, v.16, p.179-214, 1985.

RIBEIRO JÚNIOR, J.I. Análises estatísticas no SAEG. Viçosa: UFV, 2001. 301p.

SANTOS, L.W.; COELHO, M.F.B.; PIRANI, F.R. Fenologia de Lafoensia pacari A. St.-Hil. (Lythraceae) em Barra do Garças, Mato Grosso, Brasil. Revista Brasileira de Plantas Medicinais, v.11, n.1, p.12-7, 2009.

TERBLANCHÉ, F.C.; KORNELIUS, G. Essential oil constituents of the genus Lippia (Verbenaceae) - A literature review. Journal of Essential Oil Research, v.8, p.471-85, 1996. 